\title{
Complications and Intercenter Variability of Three-Column Resection Osteotomies for Spinal Deformity Surgery: A Retrospective Review of 423 Patients
}

\author{
Robert P. Norton ${ }^{1} \quad$ Kristina Bianco ${ }^{1} \quad$ Virginie Lafage $^{1} \quad$ Frank J. Schwab $^{1}$ International Spine Study Group \\ Foundation \\ ${ }^{1}$ Department of Orthopaedic Surgery, Division of Spine Surgery, NYU \\ Hospital for Joint Diseases, New York, New York, United States \\ Evid Based Spine Care J 2013;4:157-159.

\begin{abstract}
Address for correspondence Robert P. Norton, MD, New York University Hospital for Joint Diseases, 306 East 15th Street, ground floor, New York, NY 10003, United States
\end{abstract} \\ (e-mail: robertpnorton@gmail.com).
}

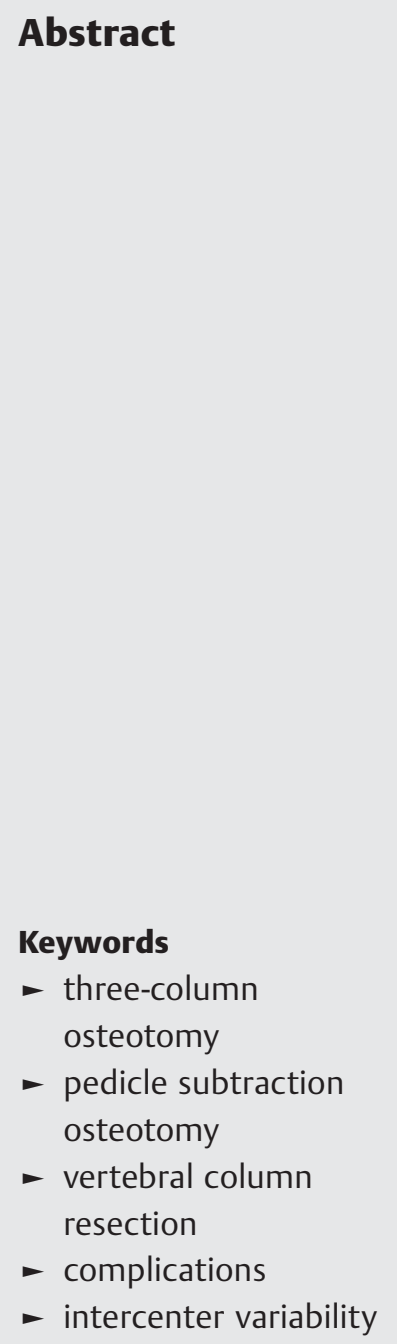

Study Type Retrospective review of a prospectively collected multicenter database. Introduction Three-column resection osteotomies (3CO), including pedicle subtraction osteotomies and vertebral column resections are performed for correction of sagittal deformity; however, they have high rates of reported complications. This study examined the incidence and intercenter variability of major intraoperative complications (IOC), postoperative complications (POC), and overall complications (IOC $+\mathrm{POC}$ ) up to 6 weeks postoperation.

Objective The aim of the study is to examine the incidence and intercenter variability of major complications associated with $3 \mathrm{CO}$.

Patients and Methods A retrospective review of patients with $3 \mathrm{CO}$ from eight different sites was performed. The incidence and types of complications were determined for the study population $(N=423)$. The analysis compared patients with one $(n=391)$ and two $(n=32)$ osteotomies, as well as patients with a thoracic osteotomy (ThO) $(n=72)$ versus a lumbosacral osteotomy $(\mathrm{LSO})(n=319)$ of the spine. Subsequent analysis was performed to compare sites with low-osteotomy volumes $(<50$ patients) to sites with large osteotomy volumes (more than 50 patients). Major blood loss (MBL) was defined as more than $4 \mathrm{~L}$.

Results Of the 423 patients, the incidence of major IOC, POC, and overall complications was 28,45 , and $58 \%$, respectively (-Table $\mathbf{1}$ ). The most common major IOC was MBL (24\%) and the most common POC was unplanned return to the operating room (OR) (19\%). Other IOC included cord deficit (2.6\%), pneumothorax (1.5\%), large vessel injury $(1.7 \%)$, nerve root injury $(1.4 \%)$, and cardiac arrest $(0.2 \%)$. Other POC included motor deficit (12.1\%), deep infection (7.6\%), acute respiratory distress/failure (4.7\%), deep venous thrombosis (3.1\%), pulmonary embolism (2.8\%), arrhythmia (1.2\%), reintubation and sepsis $(0.7 \%)$, cauda equine syndrome, myocardial infarction, visual deficit, stroke $(0.5 \%)$, and death $(0.2 \%)$. Patients with one $3 \mathrm{CO}$ had significantly less POC (43 vs. $69 \%, p<0.01$ ) and overall complications ( 57 vs. $75 \%, p<0.01$ ) than patients with two $3 \mathrm{CO}$ (-Fig. 1). IOC, MBL, and return to the OR were not significantly different

received

June 6, 2013

accepted

July 18, 2013 (c) 2013 Georg Thieme Verlag KG Stuttgart · New York
DOI http://dx.doi.org/ 10.1055/s-0033-1357364. ISSN 1663-7976. 
between groups. Patients with ThO had significantly more POC (66 vs. 39\%, $p<0.01$ ) and overall complications (76 vs. 53\%, $p<0.001$ ) than patients with LSO. Patients with LSO had more MBL ( 25 vs. $14 \%, p=0.04$ ). Patients with ThO had more unplanned return to OR ( 41 vs. $14 \%, p<0.001$ ) (-Fig. 2). The incidence of IOC was greater for the low-volume sites than high-volume sites ( 46 vs. $23 \%, p<0.001$ ). Low-volume sites had a higher frequency of patients with MBL than high-volume sites (45 vs. $18 \%, p<0.001$ ) (-Fig. 3). Patients who experienced MBL had a significantly longer operating time $(p<0.001)$ and a higher risk of developing other IOC, POC, and overall complications $(\mathrm{OR}=2.18,1.51,1.63$, respectively) than patients who did not experience substantial blood loss.

Conclusions The overall incidence of complications was $58 \%$ following $3 \mathrm{CO}$ surgery. There was significant variation in incidence of complications depending on the number, location, and experience of performing osteotomies. Risks for developing complications included having two osteotomies, ThO, surgery at a low-volume center, and blood loss more than $4 \mathrm{~L}$. With a better understanding of $3 \mathrm{CO}$ complications and risk factors, physicians may be more informed in the decision-making process of sagittal plane deformity correction.

Table 1 Incidence of IOC, POC, and overall complications for respective groups

\begin{tabular}{|l|l|l|l|l|l|l|l|}
\hline & Study population $N=423$ & $\begin{array}{l}\text { Two 3CO } \\
n=32\end{array}$ & $\begin{array}{l}\text { One 3CO } \\
\boldsymbol{n}=391\end{array}$ & $\begin{array}{l}\text { ThO } \\
\boldsymbol{n}=\mathbf{7 2}\end{array}$ & $\begin{array}{l}\text { LSO } \\
\boldsymbol{n}=\mathbf{3 1 9}\end{array}$ & $\begin{array}{l}\text { Low-vol. sites } \\
\boldsymbol{n}=\mathbf{9 6}\end{array}$ & $\begin{array}{l}\text { High-vol. sites } \\
\boldsymbol{n}=\mathbf{3 2 0}\end{array}$ \\
\hline IOC, \% & 28 & 38 & 28 & 30 & 28 & 46 & 23 \\
\hline POC, \% & 45 & 69 & 43 & 66 & 39 & 36 & 47 \\
\hline Overall comp., \% & 58 & 75 & 57 & 76 & 53 & 64 & 56 \\
\hline
\end{tabular}

Abbreviations: comp., complications; IOC, intraoperative complication; POC, postoperative complication; ThO, thoracic osteotomy; 3CO, threecolumn resection osteotomies.

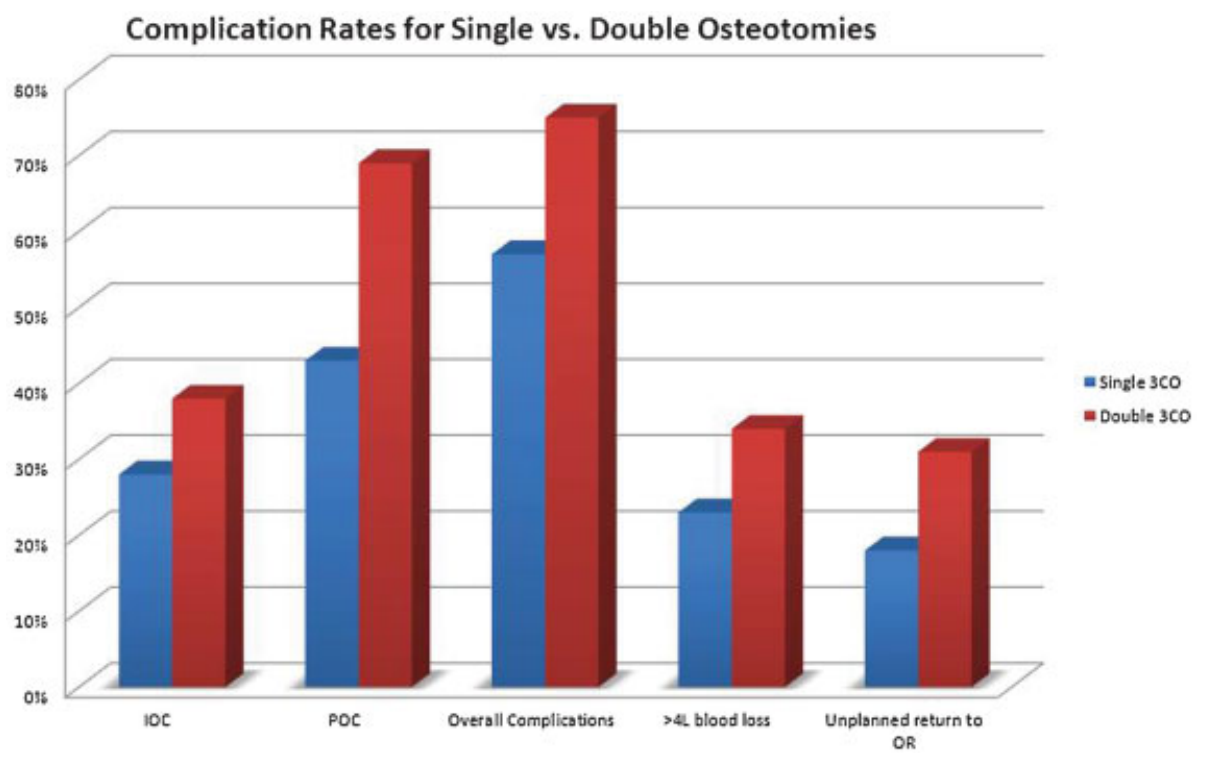

Fig. 1 Complication rates by number of three-column resection osteotomies. 


\section{Complication Rates by Osteotomy Location}

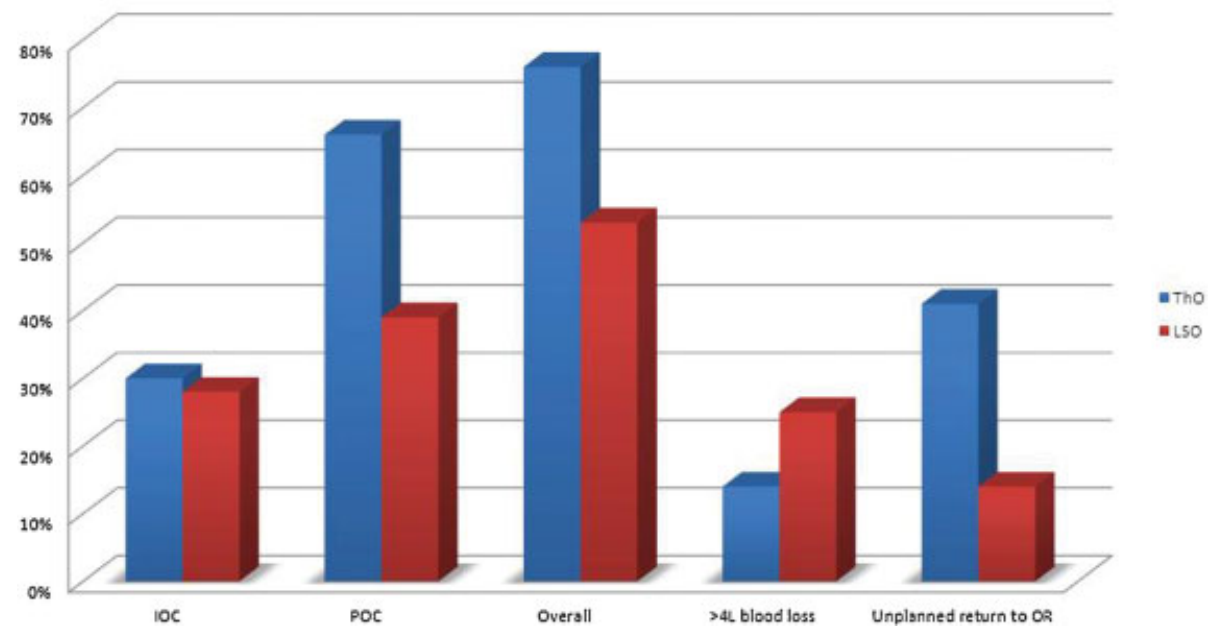

Fig. 2 Complication rates by anatomical location of three-column resection osteotomies.

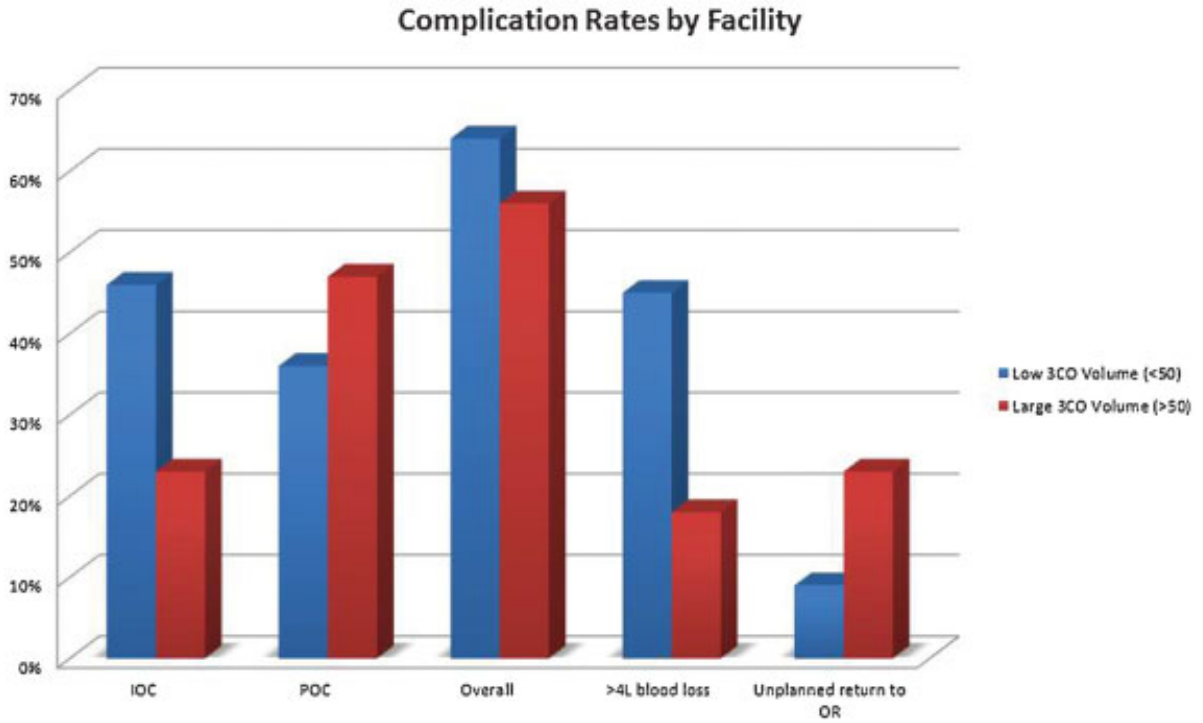

Fig. 3 Complication rates by volume of three-column resection osteotomies.

Potential Conflicts of Interest

- Robert P. Norton, MD

- Shareholder: InVivo Therapeutics

- Frank Schwab, MD

- Research grants received from: DepuySpine, NIH,

International Spine Study Group

- Consultant: Medtronic, DepuySpine

- Speaker: Medtronic

- Royalties: Medtronic

- Shareholder: Nemaris Inc

- Virginie Lafage, PhD

- Research grants received from: International Spine Study Group, SRS

- Consultant: Medtronic
- Speaker: Medtronic, DepuySpine, K2M

- Shareholder: Nemaris Inc

- International Spine Study Group Foundation

- Research grants received from: DepuySpine, Medtronic, OREF

\section{Source of Funding}

Research Grant was received from Depuy Spine.

\section{Indication of IRB Approval}

International review board approved from each participating center. 